\section{HEAT SPECTRA}

I NOTICE in NATURE, vol. i., p. 28, an account of some very important researches on Heat Spectra, made by the late Professor Magnus; and I am gratified to think that some observations which I made on the sub. ject in the years 1858 and 1859 were confirmed by this eminent German philosopher.

In a paper read before the Royal Society of Edinburgh in 1858 , I showed that rock-salt absorbs heat radiated from rock-salt in larger quantity and more powerfully than other kinds of heat; and also that the amount of absorption of rock-salt for heat increases with the thickness of the absorbing plate. These are the fourth and fifth results of Professor Magnus. His next result is very interesting, namely, that the high diathermancy of rocksalt does not depend on its small absorptive power for the different kinds of heat, but on the fact that it only radiates, and consequently only absorbs, heat of one kind ; while almost all other bodies at the temperature of $150^{\circ}$ F., emit heat which contains only a small fraction or none of those rays which are given out by rock-salt.

Certain experiments which I made in 1859 lead me to think that Professor Magnus was quite justified in his conclusion that the heat radiated and absorbed by rock-salt is a peculiar kind of heat. These experiments, which are described in the Transactions of the Royal Society of Edinburgh, are as follows. I tested the quality of the heat radiated by rock-salt at $2 \mathrm{I} 2^{\circ} \mathrm{F}$. by transmitting it through three different screens:-

$$
\begin{aligned}
& a \text { A screen of mica. } \\
& \beta \text { One of mica split by heat. } \\
& \gamma \text { One of glass. }
\end{aligned}
$$

It was found that a mica screen, which passed about 31 per cent. of ordinary lampblack heat, passed only is per cent. of rock-salt heat ; or if we call the proportion of black heat passed by the mica roo, that of rock-salt heat will be 58. Again, it was found that while 20 per cent. of lampblack heat passed through a screen of split mica, the proportion of rock-salt heat transmitted through the same screen was only $15 \frac{1}{4}$ per cent. These numbers are to one another as 100 to 76 .

Lastly, with respect to a glass screen, calling the proportion of lampblack heat which passed Ioo, that of the rock-sait heat which passed the same screen was 57 .

On these results I remark as follows:-It is already well known that rays of great refrangibility, or small wave length, pass through glass or mica more readily than those of an opposite character. The difficulty with which rocksalt heat penetrates these substances as compared with ordinary heat, might therefore lead us to infer that the wave length of this heat is greater than that of ordinary lampblack heat.

If we now look to the relative transmission of the two descriptions of heat through mica split by heat, we see that the facility of transmission is yet in favour of ordinary

\begin{tabular}{|c|c|c|c|}
\hline Nature of Screen & $\begin{array}{l}\text { Transmissi } \\
\text { Ordinary H } \\
\text { at } 2 \times 2^{\circ}\end{array}$ & & $\begin{array}{c}\text { Transmission of } \\
\text { Rock-salt Heat } \\
\text { at } 212^{\circ}\end{array}$ \\
\hline & . 100 & & . 58 \\
\hline Mica split by heat & . $\quad 100$ & & . . 76 \\
\hline
\end{tabular}
heat, but not so strikingly as with a screen of common mica. This will be seen from the following table :-

Compare this with the following table, deduced from the results given by Professor Forbes :-

$$
\begin{aligned}
& \text { Transmission of Heat Transmission of } \\
& \text { alackened Brass Black Heat } \\
& \text { Mica OI } 5 \text { inch thick. } 100 \text {. . } 52 \\
& \text { Mica split by heat. . } 100.0^{\circ} \cdot{ }^{\circ} 64
\end{aligned}
$$

From a comparison of these two tables, it will be seen that, as tested by the two substances, mica and mica split by heat, rock-salt heat at $212^{\circ} \mathrm{F}$. bears to ordinary heat of that temperature a relation similar to that which ordinary heat at $212^{\circ}$ bears to heat at $700^{\circ}$; that is to say, that just as heat of $212^{\circ}$ has a greater wave-length than heat of $700^{\circ}$, so rock-salt heat at $212^{\circ}$ has a greater wave-length than ordinary heat at that temperature. And the surface stoppage produced by splitting the mica, telling most powerfully upon heat of high temperature, or small wavelength, while the stoppage by substance is in the opposite direction, we see how the one effect tends, to a certain extent, to neutralise the other, rendering the proportions of different kinds of heat passed by split mica more nearly alike than those passed by ordinary mica. In connection with these remarks I may state that neither the radiation nor the absorption of a plate of rock-salt is sensibly influenced by roughening its surface with emery paper.

All these experiments concur in showing that heat from rock-salt possesses very great wave-length, and probably heat from a thin plate of this substance, at a low temperature, may be found to possess a greater wave-length than any other description of heat which can be exhibited.

The observations of Professor Magnus with respect to the nature of the heat from potassium chloride are very interesting; unfortunately I did not make any experiments on this substance, but I did on some others in the shape of powder.

I found that the comparative radiation at $212^{\circ}$ was as follows :-

$$
\begin{aligned}
& \text { From lamp black . . . . . . I00 } \\
& \text { Alum in powder . . . . . 100 } \\
& \text { White sugar . . . . . . . } 98.7 \\
& \text { Sulphate of potash . . . . . 88.1 } \\
& \text { Nitrate of potash . . . . . . } 867 \\
& \text { Table salt . . . . . . } 83
\end{aligned}
$$

The experiments of Prof. Magnus on the reflection of heat are also of the very greatest importance, and they strengthen the evidence (already overwhelming) in favour of that view which regards light and heat as varieties of the same agent differing in nothing except wave-length.

BALFOUR STEWART

\section{ON THE METHOD OF ASSAYING SILVER AS CONDUCTED IN THE INDIAN MINT*}

BY DR. H. E. BUSTEED, OFFG. ASSAY MASTER

THE method of assaying silver, as now in use in H.M.'s Indian Mints, is one peculiar to them; it was introcluced into the Calcutta Mint about the year 1850, and thence extended in course of time to those of Bombay and Madras.

It has been favourably reported on and described more or less in detail as an official duty by various assay officers to local Mint authorities in India; but beyond this it would appear that no atterript has been made towards giving publicity to the practical working of the process, or to making generally known the laboratory details of this method of assay.

It has been suggested to the writer that some such attempt now would be nut only interesting but useful, as after twenty years' experience of it, the assay offices in the Indian Mint must be in a position to assign its true value to a method which has been used for the assay of an immense importation and coinage of silver bullion. To render it more generally intelligible, and to show wherein the process about to be explained contrasted with those in more general use, Dr. Busteed very briefly adverted to the principles on which those processes depend for their results, omiiting details and technicalities. In modern acceptance, the principal cluty of an assayer is to ascertain the proportion of the precious metals present in any sample of mixed nietal submitted to him for examination, so that from the result of his investigation the proper value may be assigned by calculation to the mass which the sample is supposed to represent.

This the assayer effects by separation of the precious metals from the coarser ones. The most ancient means of effecting this was by the method of cupellation. He explained the principle of this method, what skill and experience it required on the part of the operator, and how it still fell short of accuracy in its results.

* From the Proceedings of the Asiatic Society of Bengal. 